\title{
On the Locus of Asymmetry in $\mathrm{UG}^{*}$
}

\section{Cedric Boeckx}

ICREA/UAB

CLT

Cedric.Boeckx@uab.cat

\begin{abstract}
In this article I advance a hypothesis concerning the locus of asymmetry in the grammar. I argue that the fundamental operation of Narrow Syntax (Merge) should be formulated in a symmetric form, and that all the sources of asymmetries should be relegated to the point of cyclic transfer (Cyclic Spell-Out, in a phase-based model).
\end{abstract}

Key words: Asymmetry, Merge, Phase, Spell-Out.

\section{Table of Contents}

1. (A)symmetry \& simplicity considerations

2. Phases: Necessary, and maybe even sufficient
3. Concluding remarks

References

\section{1. (A)symmetry \& simplicity considerations}

It is well-known that the fundamental structure-building operation Merge in its simplest, most desirable, symmetric formulation (1) leaves unaccounted for a variety of properties of human language long thought to be at the core of our speciesspecific capacity.

\section{(1) Merge $_{\text {def }}$}

Take two items (endowed with an unerasable 'edge' property; ${ }^{1}$ Chomsky (2008)) $\alpha$ and $\beta$ and form the set $\{\alpha, \beta\}: \quad \alpha_{\mathrm{e}} \oplus \beta_{\mathrm{e}}=\left\{\alpha_{\mathrm{e}}, \beta_{\mathrm{e}}\right\}$

* For valuable comments, I wish to thank Dennis Ott, Hiroki Narita, Bridget Samuels, Terje Lohndal, the editors of this issue, Ángel Gallego and Jordi Fortuny, and an anonymous reviewer. I ask the reader to bear in mind that the present paper is only an outline. For a more detailed exploration of the themes touched on here, see Boeckx (2009a).

1. Chomsky (2008:139) characterizes the 'edge' property as follows:

For a L[exical] I[tem] to be able to enter into a computation, merging with some [syntactic object], it must have some property permitting this operation. A property of an LI is called a feature, so an LI has a feature that permits it to be merged. Call this the edge-feature (EF) of the LI. 
In the absence of any asymmetry of any kind as part of Merge it is not clear how to capture basic facts about (s- \& c-)selection, theta-assignment, linear precedence, movement type ( $\mathrm{X}^{0}$ - vs. $\mathrm{XP}-$-), prosodic grouping, and so on (assuming, as I think we must, that syntax is the only source of 'generativity,' contra Jackendoff $(1997,20002))$. The source of the problem is clear: (1) is too impoverished to support the empirical burden carried by the traditional X'-schema. In the wake of Bare Phrase Structure (Chomsky 1994) a return to X'-theory is not an option. Nevertheless various proposals have been made in a minimalist context to enrich Merge, in particular to build in some asymmetry (reducing to labeling) that would then serve as the anchor (in something like the sense of Uriagereka (2008)) for interpretive asymmetries at SEM and PHON (selection, linearization, ...). ${ }^{2}$

However, all of these proposals depart from the most minimal, 'best-case' scenario regarding the character of narrow syntax in ways that are best avoided: they either take Merge to be triggered by some feature-checking operation (requiring a rich set of poorly-motivated syntactic features) and/or invoke an extra operation (vacuous Self-Merge, or Copy, or Project), thereby enriching narrow syntax considerably. I take the best-case scenario to be the one put forward in Chomsky (2004) and refined in Chomsky $(2007,2008)$, where all narrow syntax requires is a pure setformation rule (Merge) (equivalently, an unerasable edge property on all lexical items; cf. (1)). Under this characterization (a significant, and, in my view, insufficiently appreciated, departure from earlier minimalist approaches where Last Resort considerations dominated), Merge (of both the external and internal sorts) is free (Chomsky (2004:110)), which is another way of saying that syntax is fundamentally blind to the featural specifications of lexical items. ${ }^{3}$

In this contribution I would like to explore the conjecture in (2):

(2) All sources of interpretive asymmetries in UG are part of Transfer (SpellOut).

To be viable, the conjecture in (2) forces me to adopt the idea that Transfer/SpellOut is cyclic. More precisely, it requires the adoption of phase-based derivations (Chomsky (2000, 2001)), a specific cyclic-spell-out model that departs from others in two main ways: (i) phases are relatively few in number (in contrast to strongly derivational approaches that take each application of Merge to be a spell-out domain; cf. Epstein and Seely (2002), Bošković (2007)), and (ii) transfer to PHON and SEM happen at the same time (contra Marušić (2005), Richards (2008)). The conjecture in (2) can thus be reformulated as the hypothesis in (3):

2. Perhaps the first of these proposals is Collins' (2002) Locus Principle, where the label is identified with the Probe ('Locus'), which requires all instances of Merge to be triggered. For other proposals, see Hornstein (2009), Boeckx (2008a, 2009b), Narita (to appear), Irurtzun (2007), and Kayne (to appear).

3. A desirable feature of this "Merge $\alpha$ " hypothesis is that it makes narrow syntax more robust and truly uniform, immune to parametric variation, as I discuss in Boeckx (to appear-a). 
(3) Phases are the sources of all interpretive asymmetries found in UG.

The next section examines the reasons why a cyclic-spell-out model of the phase-sort is required, and how it may be able to bear the burden of proof.

\section{Phases: Necessary, and maybe even sufficient}

Chomsky (2000) elevates the long-held guiding idea that linguistic computations proceed in a cyclic fashion (see Freidin (1999), Lasnik (2006)) to a postulate, according to which syntactic derivations are divided into phases. Phases consist of a designated element (the phase-head), whose complement gets transferred to the interfaces (either immediately before a new head is introduced (Chomsky 2000), or else as soon as the next phase-head is introduced (Chomsky 2001). The phase head provides an 'edge' to host internally merged elements in addition to material introduced by external merge. Intuitively, phases impose a locality condition on syntactic computation (the same way the principle of compositionality imposes a locality condition on semantic computation). In the best case scenario phases keep the size of the workspace to a bare minimum.

Over the years, Chomsky has offered a variety of suggestive arguments in favor of a phase-based architecture of narrow syntax (for an exhaustive list, see Gallego (2007)). To my mind the most compelling argument comes from the 'logic of feature-valuation.' Assume, with Chomsky (2000), that featural interpretability is not a relevant (i.e., accessible) dimension within narrow syntax (as seems desirable, if look-ahead is to be avoided), and that instead lack of a feature-value (by hypothesis, a property accessible to narrow syntax) provides an instruction to the SEM component not to interpret the feature in question on the element bearing it. Chomsky (2001) observes that because features can come to be valued in the course of the derivation via Agree (Chomsky (2000)) it is imperative to synchronize valuation and transfer to ensure that the right instructions reach the external systems. This in effect requires Transfer to take place every time valuation does (effectively forcing unvalued features to be confined to phase-heads; Chomsky (2007, 2008; Richards 2007). ${ }^{4}$ (Note that because the process of valuation is asymmetric, it would have to take place at the phase-level if (3) is on the right track.)

Just like there are good reasons to assume that Transfer takes place more than once, there are also good reasons to assume that Transfer should not take place every time a set created by Merge is formed (contra Epstein and Seely (2002), Bošković (2007)). It stands to reason that if Transfer means 'no longer active for further computation' (the only meaning of Transfer that would not devoid phases of any syntactic content, or rob the concept of phase from any desirable consequences

4. One should not conclude from this relation between Transfer and Agree that all phase heads must carry unvalued features or that Transfer only takes place when Agree does. Other considerations may require cyclic Transfer (see Uriagereka (1999)), creating a distinction between phase heads with and without unvalued features, which may relate to the strong/weak phase distinction introduced in Chomsky (2001). For relevant discussion, see Boeckx (2009a). 
regarding computational complexity reduction) the entire output of Merge should not be transferred as it is formed, for syntax would then be still-born (Merge would cease to be set-formation, and would be equivalent to Concatenate/string-formation). At least one member of the Merge set must remain accessible for further computation (external Merge). Ideally, both Merge-set members should be given the chance to remerge with a third syntactic unit (remerger with the same original Merge-partner being ruled out via some version of Anti-locality/Vacuous Movement; Boeckx (2008c)) - if only to retain the symmetry of Merge in (1). Accordingly, the earliest Transfer point corresponds to the second phrase of a prototypical derivation. That is to say, the first phase-head corresponds to the second phrase head in the derivation. This dovetails well with Chomsky's (2000) claim that the first phase is the second VP-shell: $v$ P. ${ }^{5}$ Keeping to a conservative inventory of functional projections,${ }^{6}$ the idea that Transfer takes place every other time Merge applies yields the following pattern:

(4) a. $\left\{\operatorname{Head}_{1}{ }^{\text {Transfer }},\left\{\operatorname{Head}_{2},\left\{\operatorname{Head}_{3}{ }^{\text {Transfer }},\left\{\operatorname{Head}_{4}\right\}\right\}\right\}\right\}$
b. $\left[\mathrm{C}^{\text {Phase }}\left[\mathrm{T}\left[v^{\text {Phase }}[\mathrm{V}]\right]\right]\right]$

This result corresponds to Chomsky's (2000) claim that C and $v$ are the relevant phase heads. It also corresponds to Richards' (2006) observation that lexical subarrays have an alternating, 'fluctuating' pattern (read bottom-up), given in (5): ${ }^{7}$

\section{...-Phase-Non-Phase-Phase-Non-Phase}

I would like to take the oscillating pattern in (5) seriously and use it to anchor asymmetries of the sort discussed in section 1 . The intuition I would like to push is

5. It also fits well with the claim that any unvalued feature on a phase-head must be inherited by the non-phase head for Transfer and Agree to be synchronized; see Richard (2007), Chomsky (2007).

6. This is an idealization, but one that is not altogether unmotivated, as I argue at length in Boeckx (2008a: chap. 4), where the nature of cartographies is examined. See also Fortuny (2008).

7. Clemens Mayr (p.c.) asks what forces the pattern in (5). Specifically, why don't we find the pattern in (i)?

(i) $\{$ Phase, $\{$ Phase, $\{$ Phase, $\{$ Non-Phase $\}\}\}\}$

After all, the reasons for not taking the first output of Merge to be a phase do not seem to extend to the second instance of Merge and its relation to the third instance of Merge. If T were a phasehead, $v$ could inherit its features, and $\mathrm{T}$ would be able to host any internally merged element. I would like to claim that because what remains of the first ( $v$-)phase after spell-out is just the edge, it counts as one element for purposes of Merge, so that the second application of Merge, i.e., the creation of the next phase, corresponds to the introduction of $\mathrm{C}$. Merging $\mathrm{T}$ and the edge of the first phase is thus on a par with merging $\mathrm{V}$ and OBJ, not with merging $v$ and its complement. The intuition here is that cyclic spell-out (of the phase-type) corresponds to a rhythm that is much like a heart beat: not tic-tic-tic-tac, ..., but tic-tac-tic-tac, ... $\}$. The architectural rationale behind this is likely to be due to the fact that the pattern in (i) is not asymmetric enough for the interpretive components, which would not be able to 'label' the edge of the first phase properly, as it would be both a Phase and a non-Phase. For elaboration, see Boeckx (2009a). 
this. Transfer creates an asymmetry between what gets spelled out and what does not. Specifically, it creates an asymmetry between a (phase) head and its complement. This could be used by the interpretive systems as a substitute for any labeling algorithm currently employed to distinguish between $\mathrm{X}^{0}$ and YP. (Because information is transferred to PHON and SEM at the same time, what counts as a head at PF will also count as a head at LF, which is exactly the alignment that is empirically attested.)

Internal to YP (the spelled-out unit), the Merge-members could be distinguished (i.e., labeled) via Agree/Probing (initiated by the Phase head). To take a concrete example, the phase head $v$ takes "VP" as its complement. VP consists of V and (say) Oвл. Probing by $v$ will automatically distinguish between $\mathrm{V}$ and Oвј, ${ }^{8}$ picking out Овл as the the Goal and leaving $\mathrm{V}$ as the non-Probe (which will inherit the $\mathrm{f}$-features from $v$ ). A similar scenario would distinguish between SUBJ and $\mathrm{T}$ upon Probing by C. (Note that this 'labeling algorithm' recovers Collins' (2002) insight that that "the label is the locus" (where the 'locus' is the 'probe,' Boeckx (2008a).)

As far as I can see, this 'labeling strategy' would fail to create an unambiguous asymmetry internal to the phase-head complement if the two Merge-partners could serve as goals, that is, if they were too similar (i.e., of the same featural distribution). This turns out to be a desirable result. As several researchers (van Riemsdijk (2008), Richards (2002), Boeckx (2008a), Moro (2000)) have pointed out, domains containing too many elements of the same kind are unstable (I'd like to add: unstable at the interfaces). ${ }^{9}$ Moro (2000) in particular has suggested that the instability at issue is corrected by moving either one of the two elements that are too similar.

Evidence for this claim comes from small clauses. Moro observes (for Italian) that small clauses consisting of two DPs in situ (as opposed to small clauses consisting of a DP and a PP, say) are ruled out. Instead, one of the two DPs must move out, as illustrated here:

a. * Sono molte foto del muro la causa della rivolta

(Italian) are many pictures of-the wall the cause of-the riot 'Many pictures on the wall are the cause of the riot.'

b. $\{$ molte foto del muro/la causa della rivolta $\}$ sono \{la causa della rivolta/molte foto del muro

What this means for us is that if the symmetry of Merge (inside the complement domain of a phase) can't be resolved by Probing ('in situ'), ${ }^{10}$ it must be

8. If $v$ lacks $\phi$-features, as in the case of unaccusatives, the 'deep' object will raise outside of the firstphase complement, leaving only a ' $\mathrm{V}$ ' element (i.e., a VP) behind.

9. Richards (2002) argues that the domains in question correspond to phase-complements, exactly as the present framework demands.

10. Moro (2007) comes close to this conclusion when he defines instability within small clauses as domains of "ambiguous probing." The present contribution can be seen as an attempt to examine the consequence of this fact for labeling as a whole. 
resolved by internal Merge, that is, by invoking the edge of the phase. (It is interesting to note that both Agree and Internal Merge share the property of being made licit by the introduction of an additional head, as both Agree and Internal Merge cannot take place inside a single Merge-domain, due to Anti-locality/the logic of valuation discussed above.)

The labeling-by-phase strategy also allows us to distinguish between an 'internal' argument and an 'external' argument: the former is the argument inside the complement domain of the phase, the latter is not (it is at the edge). ${ }^{11}$ Processes that rest on this asymmetry (e.g., incorporation, idiom formation, intonational phrasing, etc.) will thus be sensitive to the distribution of phases. I take this to be a good result. For the hypothesis entertained here is more than just replacing one asymmetry (of projection, or government, or other possibilities explored in the literature) with another (phase-non-phase; equivalently, phase-edge/phase-complement). I would contend that anchoring interpretive asymmetries in a mapping asymmetry is more natural ("makes more sense") than capitalizing on disjunctions built into definitions (such as the definition of government, or X'-theory). The fact that $\mathrm{V}$ and OBJ, but not $\mathrm{V}$ and SuBJ, can form a special interpretive unit (idiom) or morphological unit (incorporation) follows much more directly from the fact that V and Oвј (but not V and SuBJ), are spelled out (delivered to the external system) as a unit, than it does from statements like the trace of OBJ (but not the trace of SUBJ) is properly governed. The government asymmetry may be real, but why should this entail that $\mathrm{V}$ and OBJ can form a unit at PHON or SEM?

The overall point of this contribution is that Free (or, as I prefer to call it, "wildtype') Merge need not be seen as giving rise to too unconstrained a theory of narrow syntax, as the (independently well-motivated) cyclic nature of the mapping to SEM and PHON can be put to use in order to, as it were, regulate wild-type Merge. Indeed, the hypothesis in (3) is very restrictive. It leaves very few analytic options open to capture the range of facts that $\mathrm{X}^{\prime}$-constructs or labels were used for.

Take, for example, the phenomenon of pied-piping. Traditionally, pied-piping is said to require some form of percolation along a projection path (see Heck (2008) for review and discussion of various modes of implementation), but more recently Cable (2007) has argued that pied-piping is the result of the way in which a Qmorpheme (the element that enters into a Probe-Goal relation with the interrogative C) is added to an already existing structure (containing a wh/indenterminate-element). If Q is adjoined (pair-Merged; cf. Chomsky (2004)), no pied-piping will take place. If $\mathrm{Q}$ is added by regular Merge (set Merge), pied-piping takes place (movement of the $w h /$ indeterminate-element to the edge of the pied-piped unit depends on whether or not $\mathrm{Q}$ enters into an Agree-relation with it). In the event of, say, clausal pied-piping (of the sort one finds in Basque or Quechua), one need not assume that the [wh]-feature on the wh/indeterminate-element must percolate up the clausal spine for pied-piping to take place. Rather, according to Cable, one must

11. Anything else will be treated as an adjunct or an oblique/applied argument, introduced by an adposition, exactly as argued in Baker (1997). 
entertain the possibility that the Q-morpheme has been added (via set-Merge) to the whole clause. Under the latter scenario, pied-piping takes place under Q-movement for the same reason that the D-head in $\{$ the man $\}$ pied-pipes its complement under raising. I will not be able to review all the evidence that Cable adduces in support of this theoretical understanding of pied-piping. I simply want to point out that in the absence of any notion of label other than what can be derived from the distribution of phase heads, Cable's analysis is the only one available in the present framework. This in turn means that the constraints on pied-piping identified by Cable ought to reduce to constraints on phase-distribution. On the face of it, this seems to be the correct result. Cable (2007) claims that no Q-morpheme can be inserted via set-Merge between a functional head and the lexical layer it immediately dominates (D and its NP complement, e.g.). If, as some (Borer (2005), Marantz (2007)) have argued, lexical layers require a functional layer to be labeled, Cable's constraint may follow from the fact that the insertion of Q between a phase (label) and its (unlabeled) complement would give rise to a $<$ Phase, Phase, Non-Phase $>$ pattern that deviates from (5) (cf. note 7). ${ }^{12}$

Another illustration of the restrictiveness of the perspective that is forced upon us given (3) comes from the domain of ellipsis. Traditional descriptions of ellipsis processes crucially refer to labels and projections (think of $V P$-ellipsis). If the only constituents that can be referred to given (3) are phase-complements, we predict that only these will be subject to deletion (when other interpretive factors such as focus/contrast are met, of course). The fact that the the best-studied cases of ellipsis (VP-ellipsis and TP-ellipsis [a.k.a. sluicing]) correspond precisely to phasecomplements is, from this perspective, very encouraging. ${ }^{13}$ One could perhaps even turn the argument around and claim that because NP-ellipsis is well-attested, D ought to be regarded as a phase (as some authors have independently argued; see Svenonius (2004), Bošković (2005), Chomsky (2008), Ott (2008), Samuels (2009), among others). ${ }^{14}$

Irurtzun (2007) cites island effects as another context where appeal to labels appears to be necessary, since under most accounts, only certain domains bearing specific labels are opaque (cf. statements like " $D P$-island", or "complex $N P$-constraint"). The fact that extraction possibilities appear to be sensitive to agreement (more accurately, to the establishment of Agree-relations) (see Boeckx (2003)) lends further credence to tying islands to phase-heads (the only sort of label available here). ${ }^{15}$ The conjunction of Free Merge (including unconstrained internal

12. To go through, this reasoning requires $\mathrm{Q}$ to be a phase-head, but this is independently required by the logic of valuation, if Cable (2007) is right in arguing that Q may carry an unvalued feature.

13. The connection between phase and ellipsis was independently made by Gengel (to appear), and Gallego and Yoshida (2007).

14. The range of ellipsis phenomena could then serve as a powerful tool to identify phases, as Ángel Gallego shows in work in progress.

15. Epstein and Obata (in press) explore the hypothesis that Improper Movement boils down to a side effect of phase-based derivations. Their study, coupled with Boeckx's (2008a) argument that Improper Movement forms a natural class with island effects, could serve as another argument in favor of implicating islands in the explanation of constrains on internal merge (displacement). 
merge) and cyclic transfer in fact forces upon us the claim that islands are mapping problems, because that's the only place where reference to certain domains and not others is possible. The well-known sensitivity of island effects to interface properties such as resumption and ellipsis suggests that this is the right direction to go, but clearly not all phase-heads turn their complements into islands, and just like ellipsis, more than mere reference to specific heads/domains will be required. However, I am only concerned here with making sure that the initial (anchoring) asymmetries fall into place, and leave a detailed examination of island properties for another occasion. ${ }^{16}$ For my present purposes, it is enough that asymmetries of any kind do not fall outside the range of transfer points.

Finally, let me briefly touch on adjunction. If adjunction takes the form of PairMerge, ${ }^{17}$ as opposed to set-Merge (Chomsky (2004)), that is, if adjunction is an irreducible asymmetric relation, the hypothesis in (3) leads us to claim that adjunction will take place at the phase-level, where asymmetries are formed. This could explain why adjunction is banned inside the first-phase complement, for example (Chomsky (1986), Bošković (2004), McCloskey (1992)). It may also account for late-merge effects associated with adjuncts (Chomsky (1993), Lebeaux (1988), Stepanov (2001), and work on scrambling/extraposition).

\section{Concluding remarks}

Kayne (1994:xiii) correctly points out at the very beginning of the preface of his important monograph on Antisymmetry that "it is difficult to attain a restrictive theory of syntax," and that "one way of making progress toward that goal is to restrict the space of available syntactic representations." With its emphasis on minimizing the space of derivational and representational possibilities, the minimalist program has certainly contributed to making our theory of Universal Grammar more restrictive. At the same time, minimalism has stressed the need for restrictiveness and naturalness to go hand in hand. Not only should the analytic options be reduced; they should also make 'good sense,' ideally 'perfect sense.' That is to say, the options entertained should not only meet demands of explanatory adequacy, they should also go beyond these, in an attempt to shed light on a few fundamental why-questions. Asymmetries should be located where they truly belong (the rationale behind Chomsky's relegation of Kayne's LCA to PF in Chomsky (1995)).

In this contribution I have made explicit a hypothesis that emerges quite naturally from the best-case scenario that all there is to narrow syntax is Merge, which

16. Building on Boeckx (2003, 2008a), Boeckx (2008b) argues that only phase-heads forcing 'immediate spell-out' cause island effects, which is the case when Pair Merge/adjunction takes place and when the phase-head bears $u$ f-features. See Boeckx (2009a) for details.

17. It is not clear that adjunction is a uniform phenomenon, or that there is only one kind of adjunct, hence it is not at all clear that a single adjunction format will suffice. Perhaps some adjuncts are introduced by Set-Merge, others by Pair-Merge. For relevant discussion, see Hornstein and Nunes (2008). 
I see at the core of Chomsky (2004). The idea that Merge is essentially free appears to give rise to a vast problem of overgeneration. Here I have proposed that overgeneration can be considerably reduced if we take seriously the idea that Transfer is cyclic (in the specific sense of Chomsky (2000)). In particular, I have suggested we reduce all the sources of asymmetry in UG to where they must exist under the best-case scenario: at the phase-level. Selection, thematic saturation, valuation, linearization, intonational breaks, and perhaps more can be seen as specific interpretive asymmetries that emerge from the way phases work. Admittedly we do not yet fully understand every detail about phases, but I think we already understand enough to sketch, as I have done here, a plausibility argument that phases could suffice to anchor the interpretive asymmetries that abound in human language and that previous work encoded lexically (in some brute force fashion, as in the original X'-schema, or by using other features to trigger Merge).

I see the proposal in (3) to follow the recent trend of 'exoskeletality' (Borer's (2005) apt term) found in many works on the lexicon. Instead of packing all the relevant information inside lexical entries, such works distribute the lexical information across various components of the grammar (especially those outside narrow syntax), with the effect that many properties once thought to be part of narrow syntax emerge as interface (epi)phenomena. The route pursued here amounts to treating endocentricity as one such epiphenomenon. Instead of letting headedness inhere in the definition of Merge, I have argued that asymmetric labeling should be defined outside of the product of Merge, in the context of phases, pretty much like lexical categories are defined contextually in Distributed and Parallel Morphologies (Borer (2005), Marantz (2007)). Perhaps one should then speak of exocentricity, or eccentricity. At any rate, to the extent the hypothesis explored here is on the right track, it argues against Hornstein's (2009) claim that endocentric labeling was the key evolutionary event in the emergence of our language faculty. My position is much closer to Chomsky's (see, e.g., Chomsky (2005)), where the key event was the emergence of edge features allowing for unrestricted Merge. I have argued elsewhere Boeckx (to appear-b) that this characterization of the 'key' evolutionary innovation captures both our ability to make infinite use of finite means and our unique lexicon. Third factor, in the form of efficient (cyclic) mapping guaranteeing a minimal workspace (phase-transfer), regulates wild-type merge, and shapes it in ways that are usable for the external systems.

To be sure, narrow syntax so conceived ("Merge $\alpha$ ") is much less lexical than in most minimalist studies on the market (especially of the crash-proof type; cf. Frampton and Gutmann (2002)), and lends itself to a far less Fregean model of semantic computation than the vast majority of semanticists are pursuing..$^{18}$ But I think we should welcome these architectural consequences. Deviance and truthconditions, key notions of crash-proof syntax models and most semantic models,

18. By contrast, the minimal, Conjunctivist semantics advocated by Pietroski (2005a, forthcoming) is ideally suited for the sort of syntactic model advocated here, and was in fact a major source of inspiration for the present proposal. For a model of phonology that also appears tailor-made for the kind of syntax I outline here, see Samuels (2009). 
are known to be interaction effects (see Ott (to appear) and Pietroski (2005b) for lucid reminders). It would be unwise to let the computational system carry such burdens.

Ultimately, when a theory of phases becomes available, we hope to be able to not only show that all asymmetries reduce to cyclic Transfer, but also to be able to explain why all the asymmetries that we observe are predicted to be the only ones to exist. This is a task for the future. My aim in this contribution was much more modest. I merely wanted to highlight a few predictions that emerge almost as corollaries from the hypothesis that all one has in narrow syntax is Merge (and third factors guaranteeing efficient computation), and show that these predictions have at least a fighting chance of being correct. Only time will tell if the optimism expressed in this contribution was fully justified.

\section{References}

Baker, Mark (1997). "Thematic roles and syntactic structure". In: Haegeman, L. (ed.). Elements of grammar: Handbook in generative syntax. Dordrecht: Kluwer, pp. 73137.

Boeckx, Cedric (2003). Islands and chains. Amsterdam: John Benjamins.

Boeckx, Cedric (2008a). Bare syntax. Oxford: Oxford University Press.

Boeckx, Cedric (2008b). No Merge is an Island. Presented at Mayfest 2008, University of Maryland, College Park.

Boeckx, Cedric (2008c). Understanding Minimalist Syntax: Lessons from Locality in Long-distance Dependencies. Oxford: Blackwell.

Boeckx, Cedric. (2009a). Elementary syntactic structures: aspects of a theory of phases (version 2). ICREA/UAB, unpublished manuscript.

Boeckx, C. (2009b). "On the nature of Merge". In: Piattelli-Palmarini, M.; J. Uriagereka, J.; Salaburu, P. (eds.). Of minds and language: A Basque encounter with Noam Chomsky. Oxford: Oxford University Press, pp. 44-57.

Boeckx, Cedric (To appear-a). "Approaching parameters from below". In: di Sciullo, A.-M.; Boeckx, C. (eds.). The Biolinguistic enterprise: New perspectives on the evolution and nature of the human language faculty. Oxford: Oxford University Press.

Boeckx, Cedric (To appear-b). "Some reflections on Darwin's Problem in the context of Cartesian Biolinguistics". In: di Sciullo, A.-M.; Boeckx, C. (eds.). The Biolinguistic enterprise: New perspectives on the evolution and nature of the human language faculty. Oxford: Oxford University Press.

Borer, Hagit (2005). Structuring Sense (2 vols.). Oxford: Oxford University Press. Bošković, Željko (2004). "Be careful where you float your quantifiers". Natural Language and Linguistic Theory 22: 681-742.

Bošković, Željko (2005). "On the locality of left branch extraction and the structure of NP”. Studia Linguistica 59: 1-45.

Bošković, Željko (2007). "On the locality and motivation of Move and Agree: An even more minimal theory". Linguistic Inquiry 38: 589-644.

Cable, Seth (2007). The grammar of Q. MIT, doctoral dissertation.

Chomsky, Noam (1986). Barriers. Cambridge, Mass.: MIT Press. 
Chomsky, Noam (1993). "A minimalist program for linguistic theory". In: Hale, K.; Keyser, S. J. (eds.). The view from Building 20. Cambridge, Mass.: MIT Press, pp. 1-52.

Chomsky, Noam (1994). Bare phrase structure. MIT Occasional Papers in Linguistics 5. Reprinted in G. Webelhuth (ed.) (1995), Government and Binding Theory and the Minimalist Program. Oxford: Blackwell, pp. 383-439.

Chomsky, Noam (1995). The minimalist program. Cambridge, Mass: MIT Press.

Chomsky, Noam (2000). "Minimalist inquiries: the framework". In: Martin, R.; Michaels, D.; Uriagereka, J. (eds.). Step by step: Essays on minimalist syntax in honor of Howard Lasnik. Cambridge, Mass.: MIT Press, pp. 89-155.

Chomsky, Noam (2001). "Derivation by phase". In: Kenstowicz, M. (ed). Ken Hale: A Life in Language. Cambridge, Mass.: MIT Press, pp. 1-52.

Chomsky, Noam (2004). "Beyond explanatory adequacy". In: Belletti, A. (ed.). Structures and beyond. New York: Oxford University Press, pp. 104-131.

Chomsky, Noam (2005). "Three factors in the language design". Linguistic Inquiry 36: $1-22$.

Chomsky, Noam (2007). "Approaching UG from below". In: Sauerland, U.; Gaertner, H.-M. (eds.). Interfaces + recursion = language? Chomsky's minimalism and the view from semantics. Mouton de Gruyter, pp. 1-30.

Chomsky, Noam (2008). “On phases”. In: Otero, C.; Freidin, R.; Zubizarreta, M.-L. (eds.). Foundational issues in linguistics. Cambridge, Mass.: MIT Press, pp. 133-166.

Collins, Chris (2002). "Eliminating labels". In: Epstein, S. D.; Seely, T. D. (eds.). Derivation and explanation in the minimalist program. Oxford: Blackwell, pp. 42-64.

Epstein, Samuel D.; Obata, Miki (In press). "Deducing Improper Movement from Phase-based C-to-T Phi-Transfer: Feature-Splitting Internal Merge". Proceedings of WCCFL 27. Somerville, Mass.: Cascadilla Press.

Epstein, Samuel D.; Seely, T. D. (2002). "Rule applications as cycles in a level-free syntax". In: Epstein, S. D.; Seely, T. D. (eds.). Derivation and explanation in the minimalist program. Oxford: Blackwell, pp. 65-89.

Fortuny, Jordi (2008). The emergence of order in syntax. Amsterdam: John Benjamins. Frampton, John; Gutmann, Sam (2002). "Crash-proof syntax". In: Epstein, S. D.; Seely, T. D. (eds.). Derivation and explanation in the minimalist program. Oxford: Blackwell, pp. 90-105.

Freidin, Robert (1999). "Cyclicity and minimalism”. In: Epstein, S. D.; Hornstein, N. (eds). Working minimalism. Cambridge, Mass.: MIT Press, pp. 95-126.

Gallego, Ángel (2007). Phase theory and parametric variation. Universitat Autònoma de Barcelona, doctoral dissertation.

Gallego, Ángel; Yoshida, Masaya (2008). "Phases and ellipsis". Presented at WCCFL 27. Gengel, Kristin (To appear). "Phases and ellipsis". In: Proceedings of NELS 37. Amherst, Mass.: GLSA.

Heck, Fabian (2008). On Pied Piping. Berlin: Mouton de Gruyter.

Hornstein, Norbert (2009). A theory of syntax. Cambridge: Cambridge University Press. Hornstein, Norbert; Nunes, Jairo (2008). "Some thoughts on adjunction". Biolinguistics 2: $57-86$.

Irurtzun, Aritz (2007). The grammar of focus at the interfaces. Euskal Herriko Unibertsitatea, doctoral dissertation. 
Jackendoff, Ray (1997). The architecture of the language faculty. Cambridge, Mass.: MIT Press.

Jackendoff, Ray (2002). Foundations of language. Oxford: Oxford University Press. Kayne, Richard S. (1994). The antisymmetry of syntax. Cambridge, Mass.: MIT Press. Kayne, Richard S. (To appear). "Antisymmetry and the lexicon". In: di Sciullo, A.M.; Boeckx, C. (eds.). The Biolinguistic enterprise: New perspectives on the evolution and nature of the human language faculty. Oxford: Oxford University Press.

Lasnik, Howard (2006). "Conceptions of the Cycle". In: Cheng, L.; Corver, N. (eds). Whmovement: Moving On. Cambridge, Mass.: MIT Press, pp. 197-216.

Lebeaux, David (1988). "Language acquisition and the form of the grammar". University of Massachusetts, Amherst, doctoral dissertation.

Marantz, Alec (2007). "Words and phases". NYU, unpublished manuscript.

Marušić, Frank (2005). "On non-simultaneous phases”. Stony Brook University, doctoral dissertation.

McCloskey, James (1992). "Adjunction, Selection and Embedded Verb Second". Linguistics Research Report 92-07.

Moro, Andrea (2000). Dynamic antisymmetry. Cambridge, Mass.: MIT Press.

Moro, Andrea (2007). "Some notes on unstable structures". Università Vita-Salute San Raffaele/Harvard University, unpublished manuscript.

Narita, Hiroki (To appear). "Reverse-engineering edge-feature: A unified theory of labeling and Agree". Biolinguistics.

Ott, Dennis (2008). Notes on noun ph(r)ases. Harvard University, unpublished manuscript.

Ott, Dennis (To appear). “Acceptability, grammaticality, and UG”. In: Putnam, M. (ed.). Derivational simplicity in minimalist syntax. Amsterdam: John Benjamins.

Pietroski, Paul M. (2005a). Events and semantic architecture. Oxford: Oxford University Press.

Pietroski, Paul M. (2005b). "Meaning before truth". In: Preyer, G.; Peter, G. (eds.). Contextualism in philosophy: Knowledge, meaning, and truth. Oxford: Oxford University Press, pp. 253-300.

Pietroski, Paul M. (Forthcoming). Semantics without truth values. Oxford: Oxford University Press.

Richards, Marc (2006). “Deriving the edge: What's in a phase?". Universitaet Leipzig, unpublished manuscript. [Revised version to appear in Syntax]

Richards, Marc (2007). "On feature inheritance: An argument from the phase impenetrability condition". Linguistic Inquiry 38: 563-572.

Richards, Norvin (2002). "A distinctness condition on linearization". MIT, unpublished manuscript.

Richards, Norvin (2008). "Lardil "case stacking" and the structural/inherent case distinction". MIT, unpublished manuscript.

van Riemsdijk, Henk (2008). "Identity Avoidance: OCP-Effects in Swiss Relatives". In: Otero, C.; Freidin, R.; Zubizarreta, M.-L. (eds.). Foundational issues in linguistics. Cambridge, Mass.: MIT Press, pp. 227-250.

Samuels, Bridget (2009). The structure of phonological theory. Harvard University, doctoral dissertation. 
Stepanov, Arthur (2001). "Late Adjunction and Minimalist Phrase Structure". Syntax 4: 94-125.

Svenonius, Peter (2004). “On the edge”. In: Adger, D.; de Cat, C.; Tsoulas, G. (eds.). Peripheries: Syntactic edges and their effects. Dordrecht: Springer, pp. 259-287.

Uriagereka, Juan (1999). "Multiple Spell-Out”. In: Epstein, S. D.; Hornstein, N. (eds.). Working minimalism. Cambridge, Mass.: MIT Press, pp. 251-282.

Uriagereka, Juan (2008). Syntactic Anchors: On Semantic Structuring. Cambridge: Cambridge University Press. 